\title{
CARTA AO PROFESSOR HEGEL: \\ BREVES CONSIDERAÇÕES SOBRE ENSINO DE FILOSOFIA
}

\author{
LETTER TO PROFESSOR HEGEL:
}

BRIEF CONSIDERATIONS ON TEACHING PHILOSOPHY

Suzano Guimarães. ${ }^{1}$

“(...) ao aprender a conhecer o conteúdo da filosofia, não se aprende apenas o filosofar, mas também já se filosofa efetivamente"

(HEGEL, 1989, p.371)

Resumo: O artigo pretende refletir sobre "metodologia do ensino de filosofia" e "formação docente" a partir de "cartas filosóficas" utilizadas como estratégia didática e instrumento de avaliação em turmas do Ensino Médio Integrado e da Licenciatura em Filosofia. Hegel foi escolhido como fundamentação teórica devido à sua longa experiência como professor e com outras atividades pedagógicas referentes às instituições de ensino e políticas públicas do Estado. Assim sendo, julgamos que seus "escritos sobre educação" podem contribuir no debate atual sobre cidadania e "como e porque ensinar e aprender" filosofia.

Palavras-Chave: Hegel; professor-filósofo; educação e cidadania; formação docente; metodologia do ensino de filosofia

\begin{abstract}
The article intends to reflect on "philosophy teaching methodology" and "teacher training" based on "philosophical letters" used as a didactic strategy and assessment instrument in classes of Integrated High School and Degree in Philosophy. Hegel was chosen as a theoretical foundation due to his long experience as a teacher and with other pedagogical activities related to State educational institutions and public policies. Therefore, we believe that his "writings on education" can contribute to the current debate on citizenship and "how and why to teach and learn" philosophy.
\end{abstract}

Key words: Hegel; professor-philosopher; education and citizenship; teacher training; philosophy teaching methodology

\footnotetext{
${ }^{1}$ Professor do Departamento de Filosofia da Universidade Federal de Pernambuco (UFPE). Membro-fundador da Sociedade Hegel Brasileira (SHB). Integrante dos Grupos de Pesquisa: 1 - Ensino de filosofia e filosofia da educação (UFPE); 2 - Sertão Filosófico (IF Sertão-PE); 3 - Núcleo de Estudos e Pesquisa em Corporeidade (IF Sertão-PE).
} 
Imaginemos a seguinte pergunta de um(a) estudante da licenciatura em filosofia: "Professor, a gente já pagou a disciplina 'Didática', mas o que a gente quer saber agora é 'como usar o que a gente aprendeu para ensinar filosofia?”'. Não responderemos, aqui e agora, mas apresentaremos uma "experiência de ensino-aprendizagem" em turmas do Ensino Médio Integrado (EMI) e da Licenciatura em Filosofia (LF) como início de possível resposta mais demorada. Neste sentido, numa perspectiva da educação formal institucionalizada e considerando os "escritos sobre educação" de Hegel, esse texto pretende refletir sobre "metodologia do ensino de filosofia" e "formação docente" no contexto do debate atual sobre cidadania e "como e porque ensinar e aprender" filosofia.

Durante o semestre letivo 2018.1, foi combinado com uma turma do $3^{\circ}$ ano do EMI que determinada atividade escolar, a saber, "Cartas filosóficas". ${ }^{2}$ (CF), valeria como avaliação da $2^{a}$ unidade programática. Tais CF foram escolhidas como "estratégia didática" e "instrumento de avaliação" tendo em vista destaques das Orientações Curriculares para o Ensino Médio (OCN/EM / v.3 / Ciências humanas e suas tecnologias / Conhecimentos de filosofia). As OCN/EM referentes aos "conhecimentos de filosofia" buscaram superar as "ambiguidades" de documentos anteriores como os Parâmetros Curriculares Nacionais para o Ensino Médio (PCNEM) e as Orientações Educacionais Complementares aos Parâmetros Curriculares Nacionais para o Ensino Médio (PCN+) e defenderam a obrigatoriedade do ensino de filosofia como "disciplina"; o que acabaria ocorrendo com a Lei n. ${ }^{\circ} 11.684 / 2008$ e depois sua exclusão com a Lei n. ${ }^{\circ}$ 13.415/2017. No que diz respeito ao "ensino de filosofia", as OCN/EM, foram elaboradas com participação de "professores(as) de filosofia" " e contribuíram para o desenvolvimento da práxis docente, enquanto educação formal institucionalizada, até a chegada da Base Nacional Comum Curricular para o Ensino Médio (BNCC/EM) no final de 2018.4. Já durante o semestre letivo 2019.1, também foi combinado com uma turma de $5^{\circ}$ período da LF que a atividade acadêmica denominada CF valeria

\footnotetext{
2 Ver também propostas semelhantes, por exemplo, em RODRIGO, L. Filosofia em sala de aula: teoria e prática para o ensino médio. Campinas, SP: Autores Associados, 2009, p.86-87; GAARDER, J. O Mundo de Sofia: Romance da história da filosofia. São Paulo: Companhia das Letras, 1995; ASPIS, R; GALLO, S. Ensinar filosofia: um livro para professores. São Paulo: Atta Mídia e Educação, 2009, p.129-149.

3 “Consultores: Antonio Edmilson Paschoal e João Carlos Salles Pires da Silva. Leitores Críticos: Ethel Menezes Rocha, Moacyr Ayres Novaes Filho e Pedro Tomaz de Oliveira Neto (...) [O] Relatório das Discussões sobre as Orientações Curriculares do Ensino Médio e a Filosofia, resultante de uma série de seminários regionais e de um seminário nacional realizados em 2004 sob a coordenação do Departamento de Políticas de Ensino Médio da Secretaria de Educação Básica do Ministério da Educação (...) é uma das peças institucionais que subsidiam o presente documento, dando-lhe as coordenadas (...)" (BRASIL, 2020j, p.14, 19).

${ }^{4}$ Ver, por exemplo, LINDBERG, C. O ensino de Filosofia e a reforma educacional: o que fazer? Disponível em: https://anpof.org/portal/index.php/en/comunidade/coluna-anpof/2052-o-ensino-de-filosofia-e-a-reformaeducacional-o-que-fazer Acesso em: 28 jun. 2020
} 
como avaliação da $1^{a}$ unidade programática. Tais CF foram escolhidas como "estratégia didática" e "instrumento de avaliação" tendo em vista destaques das Diretrizes Curriculares aos Cursos de Graduação em Filosofia ${ }^{5}$ e da Lei de Diretrizes e Bases da Educação Nacional (LDB/EN), ambas naquilo que diz respeito à "formação de professores".

Os documentos norteadores acima destacados tratam do ordenamento educacional nacional. Além desses, existem documentos locais e específicos como, por exemplo, Parâmetros Curriculares Estaduais (quando for o caso) e Projetos Pedagógicos (de cada curso e instituição) e outros de caráter geral ${ }^{6}$. Por fim, toda essa normatização deve estar em conformidade com a Constituição Federal (notadamente seu artigo 205)?.

Com efeito, a legislação educacional assevera direitos e deveres; desde o financiamento do setor até uma "simples atividade" ocorrida em sala de aula. Tais determinações são necessárias, mas não suficientes; pois somente na ação continuada dos(as) "trabalhadores(as) da educação" ocorre a efetividade dessa "estrutura e funcionamento" da educação formal institucionalizada. Contudo, as "astúcias da história" advertem: ganhar coerência na observância da letra, não significa perder o espírito na obediência ao sistema.

Dito isto, observamos que nos dois casos de atividades já destacados não houve nem insight nem formalismo, mas apenas discreta "deliberação criativa". E considerando "competências e habilidades" recomendadas pelas OCN/EM para o ensino de filosofia e pelas Diretrizes para formação de professores(as) em filosofia, selecionamos as atividades das CF como "experiência de ensino-aprendizagem".

No primeiro caso, do EMI, as competências e habilidades admitidas foram:

$\left.1^{\circ}\right)(\ldots) \cdot$ elaborar por escrito o que foi apropriado de modo reflexivo; $2^{\circ}$ ) (...) • articular conhecimentos filosóficos e diferentes conteúdos e modos discursivos nas ciências naturais e humanas, nas artes e em outras produções culturais; $\left.3^{\circ}\right)(\ldots) \cdot$ contextualizar conhecimentos filosóficos, tanto no plano de sua origem específica quanto em outros planos: o

\footnotetext{
5 "As Diretrizes foram elaboradas para o MEC-SESu por uma comissão de especialistas de ensino de Filosofia, composta pelos professores Álvaro Valls (Unisinos), Nelson Gomes (UnB) e Oswaldo Giacoia Júnior (Unicamp)" (BRASIL, 2020j, p.19, nota 1).

${ }^{6}$ Ver, por exemplo, Lei ${ }^{\circ}$ 11.741, de 16 de Julho de 2008 (Educação profissional técnica de nível médio, da educação de jovens e adultos e da educação profissional e tecnológica) e Lei no 11.645 , de 10 de Março de 2008 (História e Cultura Afro-Brasileira e Indígena).

7 “Art. 205. A educação, direito de todos e dever do Estado e da família, será promovida e incentivada com a colaboração da sociedade, visando ao pleno desenvolvimento da pessoa, seu preparo para o exercício da cidadania e sua qualificação para o trabalho" (BRASIL, 2020b).
} 
pessoal-biográfico; o entorno sócio-político, histórico e cultural; o horizonte da sociedade científico-tecnológica (BRASIL, 2020j, p.33-34)

Já no segundo caso, da LF, as competências e habilidades admitidas foram:

- Compreensão da importância das questões acerca do sentido e da significação da própria existência e das produções culturais; - Percepção da integração necessária entre a filosofia e a produção científica, artística, bem como com o agir pessoal e político; - Capacidade de relacionar o exercício da crítica filosófica com a promoção integral da cidadania e com o respeito à pessoa, dentro da tradição de defesa dos direitos humanos (BRASIL, 2020c, p.03)

Com efeito, ambos os casos estavam em sintonia com os Projetos Pedagógicos de suas respectivas instituições, que por sua vez estavam alinhados àqueles documentos norteadores já destacados. E, particularmente, no segundo caso, da LF, foram admitidas também as seguintes finalidades da educação superior expressas na LDB/EN:

CAPÍTULO IV - DA EDUCAÇÃO SUPERIOR - Art. 43. A educação superior tem por finalidade: I - estimular a criação cultural e o desenvolvimento do espírito científico e do pensamento reflexivo (...) III - incentivar o trabalho de pesquisa e investigação científica, visando o desenvolvimento da ciência e da tecnologia e da criação e difusão da cultura, e, desse modo, desenvolver o entendimento do homem e do meio em que vive (...) V - suscitar o desejo permanente de aperfeiçoamento cultural e profissional e possibilitar a correspondente concretização, integrando os conhecimentos que vão sendo adquiridos numa estrutura intelectual sistematizadora do conhecimento de cada geração (BRASIL, 2020e)

As considerações acima apenas recordam o que "professores(as) de filosofia" já conhecem e o que certa "filosofia do ensino de filosofia" provoca de reconhecimento. Nosso tipo de sociedade ainda vigente condiciona que é somente na escola ou academia que a educação acontece, mas é justamente nesses lugares que ficamos sabendo desse condicionamento. Ora, nem todo(a) educador(a) é professor(a), costumeiramente, mas não há consenso tácito de que o inverso seja verdadeiro. E a "do-discência" 8 não é uma "firula" de linguagem, mas há professores(as) e

\footnotetext{
8 'Freire (1997, p.31) cunhou a expressão 'do-discência', afirmando que 'ensinar, aprender e pesquisar lidam com dois momentos do ciclo gnosiológico: o em que se ensina e se aprende o conhecimento já existente e o que se trabalha a produção do conhecimento ainda não existente'. Nessa perspectiva a 'do-discência e a pesquisa, indicotomizáveis, são assim práticas requeridas por estes momentos gnosiológicos'. Essa condição faz parte das qualidades do professor que pensa certo" (STRECK; REDIN; ZITKOSKI, 2018, p.148)
} 
discentes que, demasiadamente, não "pensam certo". sobre isso. Ao "botar o pé" (ou "fazer uma live") numa sala de aula, o peso dessa “insustentável leveza do ser" professor(a) se expressa em cada ação intencional ou omissão espontaneísta. Atenção: muita coisa precisa acontecer para a cousa de uma aula ocorrer. O cotidiano das instituições de ensino, com seus tempos e espaços próprios e constitutivos, é o fluxo dinâmico da totalidade das atividades pedagógicas junto às ressonâncias da vida social e com determinações recíprocas e resultantes reconhecidas pelo Estado e conforme o movimento conflituoso da História. E assim como há no mínimo utensílio ordinário o máximo da memória dos povos, um simples "bordão didático" pode ser a isca para compreensão de "pensamentos complexos".

De fato, (...) a tarefa do professor, ao desenvolver habilidades, não é incutir valores, doutrinar, mas sim "despertar os jovens para a reflexão filosófica, bem como transmitir aos alunos do ensino médio o legado da tradição e o gosto pelo pensamento inovador, crítico e independente". O desafio é, então, manter (...) o recurso ao texto, sem "objetivá-lo". O profissional bem formado em licenciatura não reproduzirá em sala a técnica de leitura que o formou, transformando o ensino médio em uma versão apressada da sua graduação. Ao contrário, tendo sido bem preparado na leitura dos textos filosóficos, poderá, por exemplo, associar adequadamente temas a textos, cumprindo satisfatoriamente a difícil tarefa de despertar o interesse do aluno para a reflexão filosófica e de articular conceitualmente os diversos aspectos culturais que então se apresentam (BRASIL, 2020j, p.33, grifo nosso)

Ainda não é comum encontrar "correspondências de filósofos(as)" nas referências dos “trabalhos de conclusão de curso", uma vez que tais "fontes” dizem respeito à "assuntos privados". As "cartas pessoais" dos(as) filósofos(as) valeriam mais para compreensão de suas biografias do que suas ideias. Contudo, é inegável que cartas, anotações de aula etc., que aparecem em publicações póstumas, tenham contribuído bastante para compreensão do pensamento de filósofos(as) clássicos(as). Deixando de lado “cartas oficiais” publicadas com finalidade explícita de promover debate cultural ou ganhar sustento, recordemos, ficando apenas num célebre exemplo, uma correspondência com Bloch na qual ocorre o esclarecimento da posição de Marx e Engels sobre a "determinação da economia na história".

\footnotetext{
9 "Quem pensa certo, mesmo que, às vezes, pense errado, é quem pode ensinar a pensar certo. E uma das condições necessárias a pensar certo é não estarmos demasiado certos de nossas certezas" (STRECK; REDIN; ZITKOSKI, 2018, p.148)
} 
De acordo com a concepção materialista da história, o elemento determinante final na história é a produção e reprodução da vida real. Mais do que isso, nem eu e nem Marx jamais afirmamos. Assim, se alguém distorce isto afirmando que o fator econômico é o único determinante, ele transforma esta proposição em algo abstrato, sem sentido e em uma frase vazia (ENGELS, 2020, grifo do autor)

Neste sentido, destaquemos a importância das correspondências como fonte de pesquisa e metodologia contemporâneas ${ }^{10}$ para a "(re)descoberta" das ideias de várias filósofas "silenciadas" na história da filosofia.

Era costume que as cartas escritas por rainhas, princesas e mulheres nobres fossem queimadas após sua morte, para que passasse para a história apenas o que os homens relatavam", conta Lacerda, citando um dos motivos que dificultam o justo reconhecimento da contribuição teórica dessas mulheres (...) A participação por meios incomuns no cânone das obras filosóficas, como é o caso das cartas, chama a atenção para a necessidade de adoção de critérios e métodos de pesquisa mais amplos do que os tradicionais. "As cartas são um material cru e imerso em contexto histórico", lembra Katarina Peixoto, que, ao preparar uma proposta de trabalho para um workshop em Paderborn, identificou na correspondência entre Elizabeth da Boêmia e Descartes e em estudos escritos por mulheres sobre esse diálogo um papel fundamental da pensadora na elaboração do Tratado sobre as paixões da alma, a última obra publicada pelo filósofo, em 1649 (FERRARI, 2020, grifo nosso)

Considerando o que já foi exposto, julgamos que a atividade escolar ou acadêmica das CF cumpre papel de "exercício filosófico" relativo às "competências e habilidades" conforme os documentos norteadores recomendam. No que diz respeito ao EMI, os(as) alunos(as) elaboraram por escrito o que foi estudado de modo reflexivo, articularam conhecimentos filosóficos com outro modo discursivo de produção cultural e contextualizaram conhecimentos filosóficos com experiências no plano pessoal-biográfico, por exemplo. A atividade foi planejada para uma unidade pedagógica sobre "ética". ". Trechos de obras de filósofos incontornáveis como Platão e Aristóteles foram "comentados", mas também filósofos contemporâneos como Michael Sandel foram "discutidos". Algumas cartas foram produzidas com maior "sensibilidade estética" (envelopes com dobraduras, selos coloridos etc.) e outras com "estilo" confessional. Destacamos que a atividade

${ }^{10}$ Ver, por exemplo, PUGLIESE, N. A história da filosofia e as obras escritas por mulheres: uma nota metodológica. Disponível em: https://anpof.org/portal/index.php/en/comunidade/coluna-anpof/2003-ahistoria-da-filosofia-e-as-obras-escritas-por-mulheres-uma-nota-metodologica Acesso em: 29 jun. 2020.

${ }^{11}$ Ver ARANHA, M; MARTINS, M. Filosofando: Introdução à filosofia. São Paulo: Moderna, 2009, p.212-221; 234263. 
foi realizada em grupos já formados anteriormente para apresentação de seminários; tal procedimento visava uma "produção de conhecimento" de modo colaborativo. Já no que diz respeito à LF, os(as) estudantes compreenderam a importância da integração necessária entre filosofia e produção artística, por exemplo, e de relacionar crítica filosófica com cidadania e ensino de filosofia. Além disso, os(as) licenciandos(as) foram estimulados à criação cultural e ao trabalho de pesquisa e investigação científica, integrando conhecimentos à formação profissional. A atividade foi planejada para uma unidade pedagógica sobre "filosofia institucionalizada" ${ }^{12} \mathrm{e}$ "formação cidadã nos documentos orientadores para ensino de filosofia". ". Filósofos clássicos como Aristóteles e Kant e filósofos(as) contemporâneos(as) como Achille Mbembe e Angela Davis foram escolhidos(as) como interlocutores(as) das problemáticas propostas, mas também "pensadores(as) e poetas" foram "convidados(as) para discussão". Algumas cartas também foram produzidas com maior "sensibilidade estética" (papéis artificialmente envelhecidos, selos de cera etc.) e outras com "estilo" convencional. Destacamos duas cartas, em especial, uma pelo rigor conceitual e "humor peculiar" em diálogo com Foucault e outra para Epicteto com "personagem e neologismo" criados num enredo próximo ao valor literário dos "romances de formação".

Imaginemos, após um gole de cafezinho durante intervalo frenético entre aulas, a seguinte pergunta de um(a) colega professor(a) do EMI bastante desconfiado(a) com os resultados dessas atividades: "E os conteúdos? Depois de todo esse parangolé aí, a turma aprendeu alguma coisa? Já sabem filosofar?" Não responderemos, aqui e agora, mas apresentaremos duas breves "cartas filosóficas" imaginadas como convite à uma "conversa dialética" entre "trabalhadores(as) da educação" e continuidade daquela primeira resposta inicial mais demorada.

12 "O ensino filosófico nos situa, de maneira explícita ou implícita, diante dos limites educativos institucionais. Em virtude das decisões que sejam tomadas com respeito ao sentido outorgado ao ensino da filosofia, pode ocorrer que não se vá mais além da reprodução dos saberes estabelecidos ou se abra a possibilidade de construir nas aulas um espaço para o pensamento (...) Pouca diferença faz o fato de que tal transmissão se baseie, por exemplo, no texto de uma constituição nacional ou em certos preceitos morais ou religiosos; já que a chave é que se está utilizando a filosofia como uma simples justificadora ou promotora da difusão de valores, crenças ou ideologias que, em última instância, são os dominantes -, ou como uma fonte supostamente 'neutra' de prescrições ou normas. Mas, de todo modo, é pensável uma expressão ‘livre’ da filosofia nas instituições educativas?” (CERLET'TI, 2009, p.69-70).

13 “Fazemos referência, aqui, ao art. 27 da LDB (...) Há aqui, explicitamente, um modelo de ética, de cidadão, de moral. Já está definido nesses documentos o cenário em que a Filosofia se inclui, bem como sua finalidade" (MONTERO, 2014, p.47, 51). 


\section{CARTA AO PROFESSOR HEGEL ${ }^{14}$}

Recife, 28 de Junho de 2020

Saudações dialéticas, professor!

Desde nossa última conversa, consultei a bibliografia recomendada e fico, mais uma vez, agradecido pela gentileza em atender meu pedido. Não tratarei nessa carta sobre a pandemia. Agora já são mais de 60 mil mortos no país em pouco mais de 3 meses. Há muita tristeza e indignação; mas a "velha toupeira" não para.

Voltando ao assunto anterior sobre "ensino de filosofia", dessa vez, o fato que me chamou atenção na minha prática docente foi o resultado de uma atividade escolar e acadêmica que passei para turmas de "ensino médio integrado" e licenciatura em filosofia. Na proposta eu pedia que os(as) discentes escolhessem quaisquer filósofos(as) ou pensadores(as) e imaginassem uma correspondência com eles(as). Teve um estudante da licenciatura que ficou curioso com a ideia porque nunca tinha escrito uma carta na vida. Engraçado como a linguagem revela a época, certo? A ideia era que eles(as) fossem provocados(as) a produzir escritos "mais autorais", combinando o que aprenderam nas aulas com competências e habilidades recomendadas pelos documentos norteadores e temas propostos.

No ensino médio integrado, numa turma de $3^{\circ}$ ano, o tema foi "ética". E tudo foi combinado nos primeiros dias de aula. É o famoso "acordo didático". Às vezes escuto por aí que jovens não têm legitimidade para tratar sobre "certos assuntos". A prática escolar me diz o contrário. Nas cartas, encontrei "defesa" da mediania em Aristóteles, porém "crítica" ao seu discurso sobre as mulheres, incluindo Rousseau nessa mesma análise; também vi "apoio" à "economia de mercado", mas "proposta" de limites morais segundo ideias de justiça de certo filósofo contemporâneo. Ou seja, eles(as) estão "reaprendendo" a ver o mundo ao redor. Claro, não foi com "excelência excelsa", mas houve algum tipo de "exercício filosófico". Há método nessa ventura, pois, durante os encontros da unidade programática, fiz provocações, aulas expositivas e dialogadas, utilizei slides com imagens de notícias e trechos do livro didático para leitura crítica coletiva e discussão. Por sinal, o livro didático oferece fragmentos de obras dos(as) filósofos(as), vocabulário, sugestões de atividades e exercícios, filmes e obras literárias, imagens de artes plásticas e

\footnotetext{
${ }^{14}$ Essa parte do texto sugere as seguintes fontes: ARANHA, M; MARTINS, M. Filosofando: Introdução à filosofia. São Paulo: Moderna, 2009; BRASIL. Guia de Livros Didáticos do Programa Nacional do Livro Didático (PNLD 2018). Disponível em: http:/ /www.fnde.gov.br/pnld-2018/ Acesso em: 28 jun. 2020d; CAPES. Formação de Professores da Educação Básica. Disponível em: https://www.capes.gov.br/educacao-basica Acesso em: 28 jun. 2020; GIL, G. Drão. Disponível em: https://www.letras.mus.br/gilberto-gil/16133/ Acesso em: 28 jun. 2020 ; SÓFOCLES. Antígona. Porto Alegre: L\&PM, 2007; UFPE. Programa Institucional de Monitoria. Disponível em: https://www.ufpe.br/proacad/monitoria Acesso em: 28 jun. 2020.
} 
recortes de músicas, suplemento para professores(as) etc.; há formação cultural enquanto ocorre aprendizagem de filosofia. E todos(as) os(as) alunos(as) recebem os livros gratuitamente através do PNLD. É fundamental investigar "como eles(as) aprendem". Dia desses uma ex-aluna mui querida me contou que até hoje lembra do dia que ficou chocada numa aula sobre o "ceticismo de Hume" e com a possibilidade de ver o professor soltar o piloto da mão e ele não cair no chão. Todas as estratégias que falei antes foram planejadas buscando combinar as orientações curriculares com "relatos" deles(as) que registro sobre cada experiência educativa em todo final de semestre letivo; um procedimento recomendado para reconhecimento da nossa própria prática docente. Já na licenciatura em filosofia, numa turma de $5^{\circ}$ período, o tema foi "formação cidadã e filosofia institucionalizada". Como foi um semestre "atípico", o "acordo didático" demorou, mas o resultado compensou. Nas cartas, os(as) futuros(as) docentes problematizaram não somente sobre os temas propostos, mas também sobre as ideias dos(as) filósofos(as) preferidos(as); o que, formalmente, foi imprevisto, mas costumo brincar dizendo que "somente improvisa quem sabe o script". Foi intrigante perceber que o "contexto histórico-social" algumas vezes passou despercebido por eles(as). O que "mudou e permaneceu" das "aulas de filosofia" no Liceu? Daí a necessária passagem pelas disciplinas de "formação pedagógica" e pelas experiências dos estágios, bem como pelos editais e programas fomentados pelo poder público como, por exemplo, monitoria, extensão, Residência e PIBID. Além da consequente pesquisa na pós-graduação. Aquele mesmo registro ao final de cada semestre letivo também aplico nessas turmas. E fico até me perguntando o que estaria passando despercebido por mim agora? Ora, na licenciatura, qualquer "metodologia de ensino" adotada pelos(as) docentes é, ao mesmo tempo, admitida como "objeto de estudo" para os(as) estudantes. Por isso, durante os encontros da unidade programática, utilizei slides com imagens já utilizadas em aulas no ensino médio integrado e comentei sobre isso justamente para exemplificar "o que acontece" num "caso real". Depois, leitura crítica coletiva e discussão sobre textos selecionados. O debate sobre "instrumentalização" da filosofia nos currículos foi sempre vespeiro.

As cartas demonstraram que houve ocasião para um ensaio de "criação filosófica" entre discentes jovens e adultos(as); eles(as) "apreenderam" satisfatoriamente os "conteúdos" e "aprenderam" competências e habilidades que serão exigidas na premente "vida profissional" e que são vividas na intermitente "vida democrática". Até porque, no que diz respeito ao "ensino médio integrado", não se pretende "formar filósofos(as)", mas "cultivar" para cidadania, como aquela máxima pitagórica já dizia; e, no que diz respeito à "licenciatura em filosofia", não é preciso comentar. No Brasil, falta Antígona na bibliografia.

Aqui encerro minhas inquietações. Um aniversariante famoso desse mês é Gilberto Gil, um "artista brasileiro". Ele tem uma canção chamada "Drão" que diz assim: "Morre, nasce trigo; vive, morre pão". Acho que seria mais ou menos isso aquela tal de "suprassunção", não?

Com desejos de

"razão e liberdade",

Suzano 


\section{RESPOSTA DO PROFESSOR HEGEL ${ }^{15}$}

Berlim, 14 de Julho de 1820

Prezado professor:

Quando jovem com 14 anos de idade, imaginei uma conversa entre Marco Antônio, Otávio e Lépido - abordando questões de teoria política — na época do triunvirato, após a morte de Júlio César, na Roma antiga. Por isso, li com interesse vossa proposta de atividade escolar para o ensino da filosofia nos Ginásios.

A aprendizagem, enquanto simples repetição e memorização, é um aspecto extremamente incompleto do ensino. Em sentido oposto, a orientação voltada à reflexão e ao raciocínio próprios da juventude é igualmente unilateral, e convém ter o cuidado de mantê-la à distância desta. Se a aprendizagem se limitasse a uma simples recepção, o resultado não seria muito melhor do que se escrevêssemos frases na água; pois não é a recepção, mas somente a auto-atividade pela qual nos apoderamos de alguma coisa, e a faculdade de utilizar novamente um conhecimento, é que faz dela nossa propriedade. Assim, à recepção deve necessariamente acrescentar-se o esforço pessoal, não como uma produção de invenções, mas como uma aplicação do que foi aprendido, como um ensaio que, graças à sua utilização, busca logo chegar a outros casos singulares, a um outro material concreto. O subjetivismo é flagelo da época. Cada um quer escutar-se a si mesmo, quer ser o que fala mais alto.

A filosofia deve necessariamente ser ensinada e aprendida, assim como qualquer outra ciência. Como são poucos os que sabem que o estudo da filosofia é o verdadeiro fundamento de toda formação teórica e prática! Minha primeira tentativa de ensino deixou, pelo que ouço dizer, um preconceito desfavorável contra mim. Eu era um iniciante, é verdade, estava preso à letra de meu caderno. Uma prática de cerca de oito anos no ginásio, onde se deve constantemente manter um diálogo com os ouvintes e onde se impõe naturalmente a necessidade de ser claro e ser compreendido, proporcionou-me, desde então, uma liberdade completa. Ainda me encontro dividido dentro de mim próprio, a saber, que talvez todo o ensino filosófico dentro dos ginásios possa parecer supérfluo, que o estudo da Antiguidade seja a introdução à filosofia mais adaptada à juventude ginasial e a verdadeira segundo a sua substância. Mas, como poderia eu,

15 Essa parte do texto é resultado de uma compilação de paráfrases e citações extraídas das seguintes fontes: BOURGEOIS, B. Hegel: Os atos do espírito. São Leopoldo, RS: UNISINOS, 2004, p.112-114; 336-341; 346. HEGEL, G. Enciclopédia das ciências filosóficas em compêndio (1830), v.3, A Filosofia do Espírito. São Paulo: Loyola, 1995, p.76-77. ___ Escritos pedagógicos. Traducción e introducción Arsenio Ginzo. Madrid: Fondo de Cultura Económica, 1991, p.181 Paulista: USF. 2002, \33, p.45; \67, p.67. Fenomenologia do espírito. Petrópolis, RJ: Vozes: Bragança Principios de la filosofía del derecho o derecho natural y ciência política. Traducción y prólogo Juan Luis Vermal. Barcelona: Edhasa, 1999, p.61; \151, Agregado, p.272. Propedêutica filosófica. Lisboa: Edições 70, 1989, p.371; 377-378. KONDER, L. Hegel: a razão quase enlouquecida. Rio de Janeiro: Campus, 1991, p.02. LOSURDO, D. Hegel e a liberdade dos modernos. São Paulo: Boitempo, 2019, p.298; 301-302; 305-306; 310-311. NOVELLI, P. O ensino da filosofia segundo Hegel: contribuições para a atualidade. Trans/Form/Ação, 28(2), 2005, p.138. ROSENFIELD, D. Hegel. Rio de Janeiro: Jorge Zahar Ed., 2002, p.09-10. 
professor de ciências propedêuticas filosóficas, ficar contra minha própria especialidade e meu emprego, privando-me de pão e água?

A escola não pode ser abandonada ao arbítrio e à contingência da iniciativa privada, porque representa uma condição ética; portanto, uma passagem decisiva para todo homem, um momento essencial no desenvolvimento de seu completo caráter ético, uma espécie de etapa obrigatória na passagem da família para a sociedade civil. A escola não deve formar apenas pessoas privadas boas, mas também - e sobretudo - bons cidadãos. Na Inglaterra, crianças de seis anos são utilizadas para limpar chaminés estreitas; nas cidades industriais da Inglaterra, crianças de tenra idade são obrigadas a trabalhar, e somente aos domingos se provê de alguma forma para sua educação. O Estado tem, então, o dever absoluto de garantir que as crianças sejam educadas. Os indivíduos devem, antes de mais nada, adquirir as capacidades de satisfazer suas necessidades mediante a participação no patrimônio geral. A questão da escola se revela indissociavelmente entrelaçada à questão social. Nenhuma escola pode escapar à soberania do Estado; os poderes éticos nãoestatais - família e coletividades sociais - não podem reivindicar para si uma tal autoridade escolar. Contudo, aquilo que justifica a autoridade escolar do Estado, a saber, ser a efetividade da razão, impede-o de determinar, por objetivos propriamente estatais ou políticos, as atividades da escola. O Estado racional sabe, com efeito, que o Estado como tal não é a realização absoluta da razão: portanto, não pode querer transformar os professores que ele paga em simples agentes governamentais, sem perder-se ele próprio ao minar sua fundação absoluta. A virtude libertadora de um tal ensino público deve-se ao fato de a escola atualizar, em seu exercício garantido pela onipotência do Estado, a raiz real da liberdade espiritual, isto é, sua raiz social.

Assim encerro meus apontamentos e aguardo vossas impressões. A filosofia e seu ensino têm o mesmo destino. Aqui está a rosa, dança aqui! Hoje é dia de plantar mais uma "árvore da liberdade".

Com votos de saúde nesses tempos coléricos, 


\section{REFERÊNCIAS BIBLIOGRÁFICAS}

ARANHA, M; MARTINS, M. Filosofando: Introdução à filosofia. São Paulo: Moderna, 2009.

ASPIS, R; GALLO, S. Ensinar filosofia: um livro para professores. São Paulo: Atta Mídia e Educação, 2009.

BOURGEOIS, B. Hegel: Os atos do espírito. São Leopoldo, RS: UNISINOS, 2004.

BRASIL. Base Nacional Comum Curricular . Disponível em: http / basenacionalcomum.mec.gov.br/ Acesso em: 28 jun. 2020a.

. Constituição da República Federativa do Brasil. Disponível em:

https://www2.camara.leg.br/atividade-legislativa/legislacao/constituicao1988 Acesso em: 28 jun. 2020b.

Diretrizes Curriculares para os cursos de Filosofia. Disponível em:

http://portal.mec.gov.br/cne/arquivos/pdf/CES122002.pdf Acesso em: 28 jun. 2020c.

Guia de Livros Didáticos do Programa Nacional do Livro Didático (PNLD 2018).

Disponível em: http://www.fnde.gov.br/pnld-2018/ Acesso em: 28 jun. 2020d.

Lei $n^{\circ}$ 9.394, de 20 de Dezembro de 1996 (Diretrizes e Bases da Educação Nacional).

Disponível em: http://www.planalto.gov.br/ccivil_03/leis/19394.htm Acesso em: 28 jun. 2020e.

Lei no 11.645, de 10 de Março de 2008 (História e Cultura Afro-Brasileira e Indígena).

Disponível em: http://www.planalto.gov.br/ccivil_03/_Ato2007-2010/2008/Lei/L11645.htm. Acesso em: 28 jun. $2020 f$.

Lei $\mathrm{n}^{\circ}$ 11.684, de 02 de Junho de 2008 (Filosofia e a Sociologia como disciplinas obrigatórias nos currículos do ensino médio). Disponível em:

https://www2.camara.leg.br/legin/fed/lei/2008/lei-11684-2-junho-2008-575857-norma-pl.html. Acesso em: 28 jun. $2020 \mathrm{~g}$.

Lei $\mathrm{n}^{\circ}$ 11.741, de 16 de Julho de 2008 (Educação profissional técnica de nível médio, da educação de jovens e adultos e da educação profissional e tecnológica). Disponível em: http://www.planalto.gov.br/ccivil_03/_Ato2007-2010/2008/Lei/L11741.htm\#art2 Acesso em: 28 jun. $2020 \mathrm{~h}$.

. Lei $\mathbf{n}^{\circ}$ 13.415, de 16 de Fevereiro de 2017 (“Reforma do ensino médio"). Disponível em: http://www.planalto.gov.br/ccivil_03/_ato2015-2018/2017/lei/113415.htm Acesso em: 28 jun. 2020i.

Orientações curriculares para o ensino médio, v.3 (Ciências humanas e suas tecnologias).

Disponível em: http://portal.mec.gov.br/seb/arquivos/pdf/book_volume_03_internet.pdf

Acesso em: 28 jun. 2020j. 
Parâmetros Curriculares Nacionais para o Ensino Médio (PCN+). Disponível em: http:// portal.mec.gov.br/conaes-comissao-nacional-de-avaliacao-da-educacao-superior/195-secretarias112877938/seb-educacao-basica-2007048997/12598-publicacoes-sp-265002211 Acesso em: 28 jun. $2020 \mathrm{k}$

. Parâmetros Curriculares Nacionais para o Ensino Médio (PCNEM). Disponível em: http://portal.mec.gov.br/conaes-comissao-nacional-de-avaliacao-da-educacao-superior/195-secretarias112877938/seb-educacao-basica-2007048997/12598-publicacoes-sp-265002211 Acesso em: 28 jun. 20201.

CAPES. Formação de Professores da Educação Básica. Disponível em: https://www.capes.gov.br/educacao-basica Acesso em: 28 jun. 2020.

CERLETTI, A. O Ensino de filosofia como problema filosófico. Belo Horizonte: Autêntica, 2009.

ENGELS, F. Carta para Joseph Bloch (21-22 de Setembro de 1890). Disponível em: https://www.marxists.org/portugues/marx/1890/09/22.htm Acesso em: 29 jun. 2020.

FERRARI, M. Pensadoras ocultas. Disponível em: https:// revistapesquisa.fapesp.br/pensadorasocultas/ Acesso em: 29 jun. 2020.

GAARDER, J. O Mundo de Sofia: Romance da história da filosofia. São Paulo: Companhia das Letras, 1995.

GIL, G. Drão. Disponível em: https://www.letras.mus.br/gilberto-gil/16133/ Acesso em: 28 jun. 2020.

HEGEL, G. Enciclopédia das ciências filosóficas em compêndio (1830), v.3, A Filosofia do Espírito. São Paulo: Loyola, 1995.

Escritos pedagógicos. Traducción e introducción Arsenio Ginzo. Madrid: Fondo de Cultura Económica, 1991.

Fenomenologia do espírito. Petrópolis, RJ: Vozes: Bragança Paulista: USF. 2002.

. Principios de la filosofía del derecho o derecho natural y ciência política. Traducción y prólogo Juan Luis Vermal. Barcelona: Edhasa, 1999, \151, Agregado, p.272.

. Propedêutica filosófica. Lisboa: Edições 70, 1989.

KONDER, L. Hegel: a razão quase enlouquecida. Rio de Janeiro: Campus, 1991.

LINDBERG, C. O ensino de Filosofia e a reforma educacional: o que fazer? Disponível em: https://anpof.org/portal/index.php/en/comunidade/coluna-anpof/2052-o-ensino-de-filosofia-e-areforma-educacional-o-que-fazer Acesso em: 28 jun. 2020.

LOSURDO, D. Hegel e a liberdade dos modernos. São Paulo: Boitempo, 2019.

MONTERO, M. O Ensino de filosofia no ensino médio brasileiro: antecedentes e 
NOVELLI, P. O ensino da filosofia segundo Hegel: contribuições para a atualidade. Trans/Form/Ação, 28(2), 129-148, 2005.

PUGLIESE, N. A história da filosofia e as obras escritas por mulheres: uma nota metodológica. Disponível em: https://anpof.org/portal/index.php/en/comunidade/coluna-anpof/2003-a-historia-dafilosofia-e-as-obras-escritas-por-mulheres-uma-nota-metodologica Acesso em: 29 jun. 2020.

RODRIGO, L. Filosofia em sala de aula: teoria e prática para o ensino médio. Campinas, SP: Autores Associados, 2009.

ROSENFIELD, D. Hegel. Rio de Janeiro: Jorge Zahar Ed., 2002.

SÓFOCLES. Antígona. Porto Alegre: L\&PM, 2007.

STRECK, D; REDIN, E; ZITKOSKI, J. Dicionário Paulo Freire. Belo Horizonte: Autêntica Editora, 2018.

UFPE. Programa Institucional de Monitoria. Disponível em: https://www.ufpe.br/proacad/monitoria Acesso em: 28 jun. 2020. 